\title{
What Did Your Peers Do to You in High School?
}

\author{
Hee Jeong Yoo \\ Department of Psychiatry, Seoul National University College of Medicine, Seoul National University Bundang Hospital, Seongnam, Korea
}

Violence is omnipresent. It might be inevitable among all living organisms which experience a power imbalance. Incidents of past school violence have recently been revealed, involving entertainers and sports players among alumni of middle and high schools. Numerous former victims (or people who defined themselves as victims) began to expose the perpetrators' past violence. Some of these cases are heading toward lawsuits, and entertainment industries are swayed in their public image and contract issues. Beyond the veracity of these confessions, this phenomenon reflects societal changes, including communication modes. The cyberspace has heated the battle around who is lying. However, I found myself responding to the phenomenon in habitual ways, formulating the cases from the perspectives of victims, perpetrators, or bystanders. What led the children to bully their peers, or to keep silent about the bullying, and what made them expose the past events? What would I have done if I had been a teacher at their school, a victim, friend of a victim, or a bully?

School is a small, yet condensed society. It comprises diverse social groups, norms, rules, and inner dynamics. Tragically, negative interactions called bullying occur. Often, perpetrators are also victims of school violence and/or domestic abuse. It might be a directly observable form, such as physical and verbal bullying. Nevertheless, more frequently, it is more subtle and deep-seated, as relational bullying includes social exclusion and rejection. Relational bullying or social aggression might be more complicated, as a psychosocial syndrome involving complex interactions among abusers, victims, and their psychosocial group. Highly socially aggressive adolescents are sometimes popular children, central in their social network, and the victims have relational and mental health issues leading to inappropriate social adjustment, which hinders external intervention [1]. As peer relationships in adolescents constitute opportunities for social learning and an essential aspect of consolidating identity, both positive and negative relational experiences can greatly affect their further individuation. In this issue, an article ex-

This is an Open Access article distributed under the terms of the Creative Commons Attribution Non-Commercial License (https://creativecommons.org/licenses/by-nc/4.0) which permits unrestricted non-commercial use, distribution, and reproduction in any medium, provided the original work is properly cited. amines the effects of school bullying prevention camps on school violence perpetrators [2]. The authors report that the program helped the male perpetrators improve for various psychological profiles, while the effects were attenuated in girls with a history of trauma. In another study on this issue, $\mathrm{Na}$ et al. [3] described the association between adverse maternal childhood experiences focusing on family violence and dysfunction, and the risk of trauma experience and posttraumatic stress symptoms in the offspring. The findings of those studies are clear; the traumatic experience of parents tends to unwillingly affect the next generation. Further, these negative experiences may incapacitate psychological and educational help once the adverse behavioral outcome is clearly presented.

The behavior of youths is weaved around a value system, locus of control, and the emotional world of their parents. Therefore, with a slight leap, school classroom politics might mirror society, especially that of the previous generation, (i.e., their parents). Evidently, their behaviors are promptly evolving along changes in the society and sub-culture they belong to, through direct experiences or being mediated by media. Thus, perspectives around school violence should be more multidimensional, and prevention should be universal. Firm limitations, including zero tolerance, might be essential, in that every child needs a solid boundary and structure such as a safety line not to be crossed. Conversely, a more indepth, personalized approach aimed at the corrective developmental experience to tame past negative events and traumas might be needed, both for victims and bullies, and even for parents and teachers. Additionally, we should contemplate how to securely implement these approaches in schools and communities. Last, we might have to consider the issue of acknowledgement and disclosure. Once the victim decides to disclose the act of the perpetrator, the effect might be tremendous, it sometimes prompts the entire system to change. However, disclosure might be dangerous if it is not based on strong confidence. If children interpret their environment as a hierarchical system ruled by power and popularity, their learned helplessness begins to manifest itself. A healthy society should help youths disclose any kind of violence without 
fearing revenge, before it has evaporated as a rumor through a long and winding fight by being exposed a decade after the events.

\section{REFERENCES}

1) Xie H, Dylan J, Swift DJ, Cairns BD, Cairns RB. Aggressive behaviors in social interaction and developmental adaptation: a narrative analysis of interpersonal conflicts during early adolescence.
Soc Dev 2002;11:205-224.

2) Lee JJ, Kim JH, Kim BN. Effects of school bullying prevention camp on the adolescent perpetrators of school violence. J Korean Acad Child Adolesc Psychiatry 2021;32:43-50.

3) Na MC, Kim MD, Park JH, Jung YE, Moon DS, Yang HJ, et al. Association between maternal adverse childhood experiences and risk of post-traumatic stress disorder in the offspring. J Korean Acad Child Adolesc Psychiatry 2021;32:63-70. 